\title{
Process Design of Microalgae Slurry Pump
}

\author{
Jiayi $\mathrm{Li}^{1, \mathrm{a}}$, Yinhang $\mathrm{Qu}^{1, \mathrm{a}}$, Yu Gong ${ }^{1, \mathrm{a}}$, Changyan Yang ${ }^{1,2^{*}}$, Bohan Yang ${ }^{1}$, Peng Liu ${ }^{1}$, Bo \\ Zhang $^{1 *}$, Yigang Ding ${ }^{1}$ \\ 1: Key Laboratory for Green Chemical Process of Ministry of Education, Hubei Key Laboratory of Novel \\ Chemical Reactor and Green Chemical Technology, School of Chemical Engineering and Pharmacy, \\ Wuhan Institute of Technology, Hubei, China \\ 2: Hubei Key Laboratory for Processing and Application of Catalytic Materials, Huanggang Normal \\ University, Hubei, China \\ a: These three authors contribute to this work equally.
}

Received June 21, 2020; Accepted July 21 2020; Published July 25, 2020

\begin{abstract}
Microalgae are a renewable source of dietary supplements, bioactive compounds, and potential energy. Once harvested, the microalgal medium is dewatered to form a slurry for downstream processing. This article outlines a process design for pumping the microalgae slurry. The pump requirements for delivering the Chlorella slurry with 5, 10 or $20 \mathrm{wt} \%$ solids at one tonne per hour $(1,000 \mathrm{~kg} / \mathrm{h})$ and 10 bar were calculated. The $5 \mathrm{wt} \%$ microalgae slurry is a Newtonian fluid with a viscosity of $1.95 \mathrm{mPa} \cdot \mathrm{s}$. The $10 \mathrm{wt} \%$ and $20 \mathrm{wt} \%$ microalgae slurries are non-Newtonian fluids, whose viscosity depends on the shear rate $(\gamma)$. The viscosity of $10 \mathrm{wt} \%$ and $20 \mathrm{wt} \%$ microalgae slurries is $1.504\left(\gamma=50 \mathrm{~s}^{-1}\right) / 1.155\left(\gamma=100 \mathrm{~s}^{-1}\right)$ and $1.844\left(\gamma=50 \mathrm{~s}^{-1}\right) / 1.219\left(\gamma=100 \mathrm{~s}^{-1}\right) \mathrm{mPa} \cdot \mathrm{s}$, respectively. The pump power requirements are mainly governed by the delivery pressure. The effect of the pipe length and the number of elbows is negligible. The effective power of the pump is calculated as $0.267-0.275 \mathrm{~kW}$. To fulfill this duty, a ZGB type single-stage single-suction centrifugal slurry pump can be selected, which would provide enough shear rate to reduce the viscosity of the microalgae slurry and give required shaft power.
\end{abstract}

Keywords: Microalgae Slurry; Slurry Pump; Process Design; Viscosity; Pump Power

\section{Introduction}

Microalgae are a source of dietary supplements, bioactive compounds, and potential energy, which have been invested extensively $[1,2]$. Generally, the microalgal culture has a very dilute concentration of 0.1-0.5 wt\% dry solids [3]. Currently, the proposed harvesting process is using a series of mechanical unit operations to dewater the microalgae medium to a level of $\sim 20 \mathrm{wt} \%$ dry solids [4], which is considered as a less energy intensive processing option than completely drying microalgae [5]. The slurry after dewatering is considerably more viscous, but it is still a flowable slurry. Thus, it only needs to be transported to downstream processing facility using a slurry pump. Downstream

*Corresponding author: ychy1969@163.com,bzhang_wh@foxmail.com 
processing of microalgae may include drying [6], extraction to yield biochemicals [7], and hydrothermal liquefaction [8] or pyrolysis to produce bio-fuels [9, 10]. The slurry pump is the key equipment for transporting the feedstock.

This paper provides a simple process design for pumping microalgae slurry. The purpose is to provide a tutorial for calculating the power requirement for pumping of various microalgae slurries, and provide data support when selecting pumps. The effect of the pipe length and the number of elbows was also discussed.

\section{Methodology}

\section{Process Description}

A microalgae flow is pumped by a slurry pump from a storage tank to the downstream processing facility. The process is illustrated in Figure 1, in which the processing facility is assumed to be a drying unit. The calculation of the drying process is not within the scope of this article.

The flow rate of the microalgal slurry is $1,000 \mathrm{~kg} / \mathrm{h}$, and the solid content is $5 \mathrm{wt} \%$, $10 \mathrm{wt} \%$ or $20 \mathrm{wt} \%$. The temperature of the slurry is $25^{\circ} \mathrm{C}$ and the pressure is $1 \mathrm{bar}$. The duty of the slurry pump is to pressurize the flow to $10 \mathrm{bar}$, and the efficiency of the pump is $70 \%$. The slurry is delivered through 100 meters of PVC pipe (diameter $0.1 \mathrm{~m}$ ) and three $90^{\circ}$ elbows to the top of the dryer.

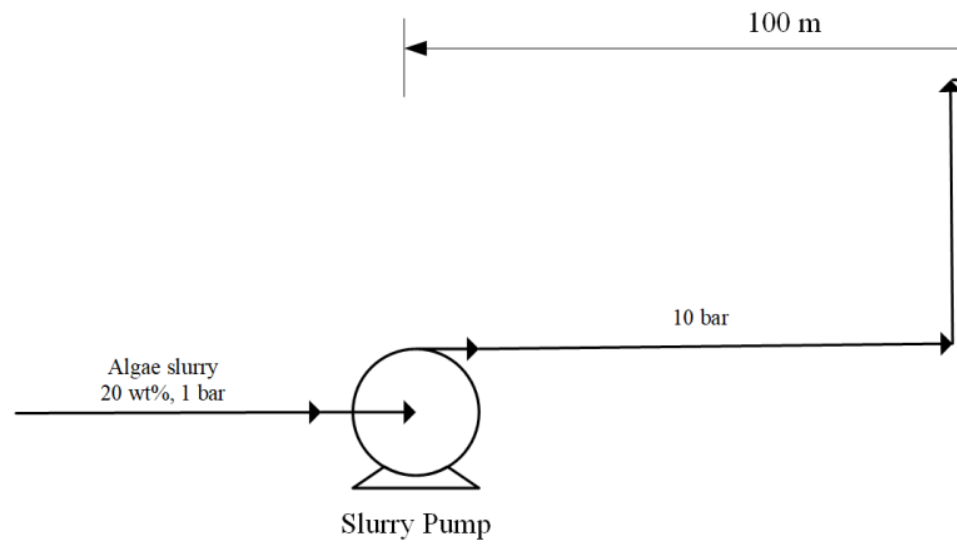

Figure 1. Process for microalgae pumping and drying

\section{Microalgae}

Green microalga Chlorella sp. is assumed to be grown autotrophically, harvested, and concentrated to a solid content of up to $20 \mathrm{wt} \%$ via a series of dewatering processes. The detailed design of the dewatering process can be found in the literature [3]. The elemental composition and biochemical components of Chlorella $s p$. have been summarized in our previous study [11]. 


\section{Results and Discussion}

Viscosity of 5,10 , and 20 wt\% Microalgal Slurry

The Chlorella slurry with a solid content of $5 \mathrm{wt} \%$ is a Newtonian fluid. The viscosity can be calculated by the following formula [12]:

$$
\mu_{\text {eff }}=1.9 \times 10^{-5} \times C+1.0 \times 10^{-3}
$$

where $\mu_{\text {eff }}(\mathrm{Pa} \cdot \mathrm{s})$ is the effective viscosity, and $C$ is the microalgae concentration and its unit is $\left(\mathrm{kg} / \mathrm{m}^{3}\right)$. Assuming the $5 \mathrm{wt} \%$ concentration is the percent weight $/$ volume $(\% \mathrm{w} / \mathrm{v})$, Equation 1 becomes:

$$
\mu_{\text {eff }}=1.9 \times 10^{-5} \times 50+1.0 \times 10^{-3}=1.95 \mathrm{mPa} \cdot \mathrm{s}
$$

The Chlorella slurry with a solid content higher than $6 \mathrm{wt} \%$ is considered as nonNewtonian fluid. Its viscosity depends on the shear rate and follows the Herschel-Bulkley model:

$$
\eta=K|\Upsilon|^{n-1}+\tau_{y}|\Upsilon|^{-1}
$$

where $\eta$ is the viscosity, $\tau_{y}$ is the yield stress, $K$ is the consistency, $n$ is the flow index, and $\gamma$ is the shear rate $\left[\mathrm{s}^{-1}\right]$. The Herschel-Bulkley parameters for the Chlorella slurry can be found in the literature as follows [13]:

Table 1. Herschel-Bulkley parameters for the Chlorella slurry

\begin{tabular}{ccc}
\hline Solid content & $\mathbf{1 0 \%}$ & $\mathbf{2 0 \%}$ \\
\hline$\tau_{y}(\mathrm{mPa})$ & 50.56 & 80.1 \\
$K\left(\mathrm{MPa} \cdot \mathrm{S}^{\mathrm{n}}\right)$ & 0.103 & 0.011 \\
$n$ & 1.4 & 1.79 \\
\hline
\end{tabular}

For the $10 \mathrm{wt} \%$ microalgal slurry, when $\gamma$ is $50 \mathrm{~s}^{-1}$,

$$
\begin{aligned}
& \eta=0.103 \times 50^{1.4-1}+50.56 \times 50^{-1}=1.504 \mathrm{mPa} \cdot \mathrm{s} \\
& \text { When } \gamma \text { is } 100 \mathrm{~s}^{-1}, \\
& \eta=0.103 \times 100^{1.4-1}+50.56 \times 100^{-1}=1.155 \mathrm{mPa} \cdot \mathrm{s}
\end{aligned}
$$

For the $20 \mathrm{wt} \%$ microalgal slurry, when $\gamma$ is $50 \mathrm{~s}^{-1}$,

$$
\begin{aligned}
& \eta=0.011 \times 50^{1.79-1}+80.1 \times 50^{-1}=1.844 \mathrm{mPa} \cdot \mathrm{s} \\
& \text { When } \gamma \text { is } 100 \mathrm{~s}^{-1}, \\
& \eta=0.011 \times 100^{1.79-1}+80.1 \times 100^{-1}=1.219 \mathrm{mPa} \cdot \mathrm{s}
\end{aligned}
$$

Therefore, the viscosity of 5, 10, and $20 \mathrm{wt} \%$ Chlorella slurries was $1.95 \mathrm{mPa} \cdot \mathrm{s}$, $1.155 \mathrm{mPa} \cdot \mathrm{s}\left(\right.$ at $\left.\gamma=100 \mathrm{~s}^{-1}\right)$, and $1.219 \mathrm{mPa} \cdot \mathrm{s}\left(\right.$ at $\gamma=100 \mathrm{~s}^{-1}$ ), respectively. The viscosity of the microalgae slurry mainly depends on the fluid type.

\section{Slurry Pump Design}

This section calculates the power and equipment selection of the slurry pump. The calculation considers three kinds of algal slurry concentration, 100 meters of pipeline length, 10 meters of tower height, and three $90^{\circ}$ right angle elbows. The density of Chlorella slurry is not available in the literature. Therefore, it is assumed that the density 
of Chlorella slurry is similar to that of Nannochloropsis salina [14]. Therefore, the density of 5,10 , and $20 \mathrm{wt} \%$ microalgae slurries are $1,009,1,020$, and $1,042 \mathrm{~kg} / \mathrm{m}^{3}$, respectively.

5 wt\% Microalgae Slurry

The volumetric flow rate is calculated as:

$$
q_{v}=q_{m} / \rho=1000 / 1009=0.991 \mathrm{~m}^{3} / \mathrm{h}
$$

Flow velocity in the pipe is:

$$
u=\frac{q_{v}}{\frac{\pi}{4} d^{2}}=\frac{0.991}{\frac{\pi}{4} \times 0.1^{2}}=126.188 \mathrm{~m} / \mathrm{h}=0.035 \mathrm{~lm} / \mathrm{s}
$$

Because the $5 \mathrm{wt} \%$ microalgal slurry belongs to Newtonian fluid, the viscosity is constant. So, Reynolds number $(\mathrm{Re})$ is calculated as

$$
\operatorname{Re}=\frac{d u \rho}{\mu}=\frac{0.1 \times 0.0351 \times 1009}{0.00195}=1813.728<2000
$$

Reynolds number is less than 2000, so the fluid is a laminar flow. Friction coefficient is

$$
\lambda=\frac{64}{\operatorname{Re}}=\frac{64}{1813.728}=0.0353
$$

According to the Chemical Engineering handbook [15], for the $90^{\circ}$ elbow, the coefficient of local resistance and the equivalent length ratio are:

$\zeta=0.75$

$$
l_{e} / d=35
$$

The total resistance of the pipeline is:

$$
\begin{gathered}
\sum h_{f}=\left(\lambda \frac{\sum l_{i}}{d}+\sum \zeta_{i}\right) \frac{u^{2}}{2}=\left[0.0353 \times\left(\frac{100}{0.1}\right)+3 \times 0.75\right] \times \frac{0.0351^{2}}{2}=0.0231 \mathrm{~J} / \mathrm{kg} \\
\sum H_{f}=\frac{\sum h_{f}}{g}=\frac{0.0231}{9.81}=0.00236 \mathrm{~m}
\end{gathered}
$$

Assuming the horizontal pipe is the datum, Bernoulli equation is listed as:

$$
z_{1}+\frac{u_{1}^{2}}{2 g}+\frac{p_{1}}{\rho g}+H_{e}=z_{2}+\frac{u_{2}^{2}}{2 g}+\frac{p_{2}}{\rho g}+\sum H_{f}
$$

where, $\mathrm{z}_{2}-\mathrm{Z}_{1}=10 \mathrm{~m}, \mathrm{u}_{1}=0, \mathrm{u}_{2}=0.0351 \mathrm{~m} / \mathrm{s}, \mathrm{P}_{1}=1$ bar, $\mathrm{P}_{2}=10$ bar

Pump head is calculated as

$$
H_{e}=10+\frac{0.0351^{2}}{2 \times 9.81}+\frac{9 \times 10^{5}}{1009 \times 9.81}+0.00236=100.927 \mathrm{~m}
$$

The effective power of the pump is

$$
P_{e}=q_{v} \rho g H_{e}=\frac{0.991}{3600} \times 1009 \times 9.81 \times 100.927=0.275 \mathrm{~kW}
$$


The pump shaft power is

$$
P=\frac{P_{e}}{\eta}=\frac{0.275}{0.7}=0.393 \mathrm{~kW}
$$

$10 w t \%$ Microalgae Slurry

The volumetric flow rate is

$$
q_{v}=q_{m} / \rho=1000 / 1020=0.98 \mathrm{~m}^{3} / \mathrm{h}
$$

Flow velocity in the pipe:

$$
u=\frac{q_{v}}{\frac{\pi}{4} d^{2}}=\frac{0.98}{\frac{\pi}{4} \times 0.1^{2}}=124.891 \mathrm{~m} / \mathrm{h}=0.0347 \mathrm{~m} / \mathrm{s}
$$

Because the $10 \mathrm{wt} \%$ microalgal slurry is non-Newtonian fluid, when $\gamma=50 \mathrm{~s}^{-1}$, the viscosity $\eta$ is $1.504 \mathrm{mPa} \cdot \mathrm{s}$. Reynolds number is

$$
\operatorname{Re}_{I}=\frac{d u \rho}{\eta}=\frac{0.1 \times 0.0347 \times 1020}{1.504 \times 10^{-3}}=2353.32>2000,
$$

Reynolds number is higher than 2000 , so the fluid is a turbulent flow. Then, the modified Blasius equation can be applied:

$$
\lambda=\frac{a}{\operatorname{Re}_{I}^{b}}
$$

where turbulent constants $\mathrm{a}$ and $\mathrm{b}$ are the function of the flow behavior index (n) with $a=0.3104 n^{0.105}, b=0.2495 n^{-0.217}$, and $\mathrm{n}=1.4$. Substitute these values into the equation to obtain $\mathrm{a}=0.3216, \mathrm{~b}=0.232$, and $\lambda=0.0531$.

The total resistance of the pipeline is:

$$
\sum H_{f}=\left(\lambda \frac{\sum l_{i}}{d}+\sum \zeta_{i}\right) \frac{u^{2}}{2 g}=\left[0.0531 \times\left(\frac{100}{0.1}\right)+3 \times 0.75\right] \times \frac{0.0347^{2}}{2 \times 9.81}=0.00339 \mathrm{~m}
$$

Bernoulli equation gives the pump head as:

$$
H_{e}=10+\frac{0.0347^{2}}{2 \times 9.81}+\frac{9 \times 10^{5}}{1020 \times 9.81}+0.00339=99.948 m
$$

The effective power of the pump is

$$
P_{e}=q_{v} \rho g H_{e}=\frac{0.98}{3600} \times 1020 \times 9.81 \times 99.948=0.272 \mathrm{~kW}
$$

The pump shaft power is

$$
P=\frac{P_{e}}{\eta}=\frac{0.272}{0.7}=0.389 \mathrm{~kW}
$$

When $\gamma=100 \mathrm{~s}^{-1}$, the viscosity $\eta$ is $1.155 \mathrm{mPa} \cdot \mathrm{s}$. Reynolds number is

$\operatorname{Re}_{I}=\frac{d u \rho}{\eta}=\frac{0.1 \times 0.0347 \times 1020}{1.155 \times 10^{-3}}=3064.42>2000$

The fluid is a turbulent flow. The modified Blasius equation gives 
$\lambda=\frac{a}{\operatorname{Re}_{I}^{b}}, a=0.3104 n^{0.105}, b=0.2495 n^{-0.217}, \mathrm{n}=1.4$. Substitute these values into the equation to obtain:

$\mathrm{a}=0.3216, \mathrm{~b}=0.232, \lambda=0.0499$

The total resistance of the pipeline is:

$\sum H_{f}=\left(\lambda \frac{\sum l_{i}}{d}+\sum \zeta_{i}\right) \frac{u^{2}}{2 g}=\left[0.0499 \times\left(\frac{100}{0.1}\right)+3 \times 0.75\right] \times \frac{0.0347^{2}}{2 \times 9.81}=0.00321 \mathrm{~m}$

Bernoulli equation gives:

$H_{e}=10+\frac{0.0347^{2}}{2 \times 9.81}+\frac{9 \times 10^{5}}{1020 \times 9.81}+0.00321=99.948 m$

The effective power of the pump is

$P_{e}=q_{v} \rho g H_{e}=\frac{0.98}{3600} \times 1020 \times 9.81 \times 99.948=0.272 \mathrm{~kW}$

The pump shaft power is

$$
P=\frac{P_{e}}{\eta}=\frac{0.272}{0.7}=0.389 \mathrm{~kW}
$$

20 wt\% Microalgae Slurry

The volumetric flow rate is

$$
q_{v}=q_{m} / \rho=1000 / 1042=0.96 \mathrm{~m}^{3} / \mathrm{h}
$$

Flow velocity in the pipe is

$$
u=\frac{q_{v}}{\frac{\pi}{4} d^{2}}=\frac{0.96}{\frac{\pi}{4} \times 0.1^{2}}=122.254 \mathrm{~m} / \mathrm{h}=0.034 \mathrm{~m} / \mathrm{s}
$$

Because the $20 \mathrm{wt} \%$ microalgal slurry is non-Newtonian fluid, when $\gamma=50 \mathrm{~s}^{-1}$, the viscosity $\eta$ is $1.844 \mathrm{mPa} \cdot \mathrm{s}$. Reynolds number is

$$
\operatorname{Re}_{I}=\frac{d u \rho}{\eta}=\frac{0.1 \times 0.034 \times 1042}{1.844 \times 10^{-3}}=1921.25<2000
$$

Reynolds number is less than 2000, so the fluid is a laminar flow. Friction coefficient is

$$
\lambda=\frac{64}{\operatorname{Re}}=\frac{64}{1921.25}=0.0333
$$

The total resistance of the pipeline is:

$$
\sum H_{f}=\left(\lambda \frac{\sum l_{i}}{d}+\sum \zeta_{i}\right) \frac{u^{2}}{2 g}=\left[0.0333 \times\left(\frac{100}{0.1}\right)+3 \times 0.75\right] \times \frac{0.034^{2}}{2 \times 9.81}=0.00209 \mathrm{~m}
$$

According to the Bernoulli equation, the pump head is 


$$
H_{e}=10+\frac{0.034^{2}}{2 \times 9.81}+\frac{9 \times 10^{5}}{1042 \times 9.81}+0.00209=98.048 m
$$

The effective power of the pump is

$$
P_{e}=q_{v} \rho g H_{e}=\frac{0.96}{3600} \times 1042 \times 9.81 \times 98.048=0.267 \mathrm{~kW}
$$

The pump shaft power is

$$
P=\frac{P_{e}}{\eta}=\frac{0.267}{0.7}=0.382 \mathrm{~kW}
$$

When $\gamma=100 \mathrm{~s}^{-1}$, the viscosity $\eta$ is $1.219 \mathrm{mPa} \cdot \mathrm{s}$. Reynolds number is

$\operatorname{Re}_{I}=\frac{d u \rho}{\eta}=\frac{0.1 \times 0.034 \times 1042}{1.219 \times 10^{-3}}=2906.32>2000$

Then, the modified Blasius equation is applied:

$\lambda=\frac{a}{\operatorname{Re}_{I}^{b}}, a=0.3104 n^{0.105}, b=0.2495 n^{-0.217}, \mathrm{n}=1.79$. Substitute these values into the equation to obtain $\mathrm{a}=0.33, \mathrm{~b}=0.22$, and $\lambda=0.0571$.

The total resistance of the pipeline is

$$
\sum H_{f}=\left(\lambda \frac{\sum l_{i}}{d}+\sum \zeta_{i}\right) \frac{u^{2}}{2 g}=\left[0.0571 \times\left(\frac{100}{0.1}\right)+3 \times 0.75\right] \times \frac{0.034^{2}}{2 \times 9.81}=0.0035 \mathrm{~m}
$$

Bernoulli equation gives the pump head as:

$$
H_{e}=10+\frac{0.034^{2}}{2 \times 9.81}+\frac{9 \times 10^{5}}{1042 \times 9.81}+0.0035=98.05 \mathrm{~m}
$$

The effective power of the pump is

$$
P_{e}=q_{v} \rho g H_{e}=\frac{0.96}{3600} \times 1042 \times 9.81 \times 98.05=0.267 \mathrm{~kW}
$$

\begin{tabular}{|c|c|c|c|c|c|}
\hline \multirow{2}{*}{ Parameters } & \multirow{2}{*}{5 wt \% } & \multicolumn{2}{|l|}{$10 \mathrm{wt} \%$} & \multicolumn{2}{|l|}{$20 \mathrm{wt} \%$} \\
\hline & & $\gamma=50 \mathrm{~s}^{-1}$ & $\gamma=100 \mathrm{~s}^{-1}$ & $\gamma=50 \mathrm{~s}^{-1}$ & $\gamma=100 \mathrm{~s}^{-1}$ \\
\hline Viscosity $(\mathrm{mPa} \cdot \mathrm{s})$ & 1.95 & 1.504 & 1.155 & 1.844 & 1.219 \\
\hline Effective power $(\mathrm{kW})$ & 0.275 & 0.272 & 0.272 & 0.267 & 0.267 \\
\hline Shaft power $(\mathrm{kW})$ & 0.393 & 0.389 & 0.389 & 0.382 & 0.382 \\
\hline
\end{tabular}

The pump shaft power is

$$
P=\frac{P_{e}}{\eta}=\frac{0.267}{0.7}=0.382 \mathrm{~kW}
$$

Table 2. Power requirements for microalgae slurry pump

Table 2 summarizes the calculation results. For the above-mentioned fluid that requires high-lift delivery, a ZGB type pump can be used, which is a single-stage singlesuction centrifugal slag/slurry pump. The typical processing shear rates of centrifugal pumps are within a range of 5 to $300 \mathrm{~s}^{-1}$ [16], which will help reduce the viscosity [17]. Because the diameter of the pipeline is $100 \mathrm{~mm}$, the 100ZGB type slurry pump can be selected. 


\section{Effect of Pipe Length on Pump Power}

It is assumed that the $20 \mathrm{wt} \%$ microalgae slurry was pumped from the storage tank to the facility. This section discusses the effect of the pipe length on the power requirement of the pump, as the length of the pipe increases to 500 meters and 1,000 meters.

When $\gamma$ is $50 \mathrm{~s}^{-1}$ and the pipe length is $500 \mathrm{~m}$, the total resistance of the pipeline is: $\sum H_{f}=\left(\lambda \frac{\sum l_{i}}{d}+\sum \zeta_{i}\right) \frac{u^{2}}{2 g}=\left[0.0333 \times\left(\frac{500}{0.1}\right)+3 \times 0.75\right] \times \frac{0.034^{2}}{2 \times 9.81}=0.00994 \mathrm{~m}$

Pump head is calculated as:

$$
H_{e}=10+\frac{0.034^{2}}{2 \times 9.81}+\frac{9 \times 10^{5}}{1042 \times 9.81}+0.00994=98.056 m
$$

The effective power of the pump is

$$
P_{e}=q_{v} \rho g H_{e}=\frac{0.96}{3600} \times 1042 \times 9.81 \times 98.056=0.267 \mathrm{~kW}
$$

When the pipe length is $1000 \mathrm{~m}$, the total resistance of the pipeline is:

$\sum H_{f}=\left(\lambda \frac{\sum l_{i}}{d}+\sum \zeta_{i}\right) \frac{u^{2}}{2 g}=\left[0.0333 \times\left(\frac{1000}{0.1}\right)+3 \times 0.75\right] \times \frac{0.034^{2}}{2 \times 9.81}=0.0198 \mathrm{~m}$

Head developed is

$$
H_{e}=10+\frac{0.034^{2}}{2 \times 9.81}+\frac{9 \times 10^{5}}{1042 \times 9.81}+0.0198=98.066 m
$$

The effective power of the pump is

$$
P_{e}=q_{v} \rho g H_{e}=\frac{0.96}{3600} \times 1042 \times 9.81 \times 98.066=0.267 \mathrm{~kW}
$$

When the pipeline length is increased to 500 meters or 1000 meters, it does not have much impact on the pump power.

\section{Effect of Number of Elbows on Pump Power}

This section discusses the effect of the numbers of elbows on the power requirement of the pump, as the numbers of elbows increases from 3 to 10. It is assumed that the $20 \mathrm{wt} \%$ microalgae slurry was pumped from the storage tank to the facility through $100 \mathrm{~m}$ pipe and elbows.

When $\gamma$ is $50 \mathrm{~s}^{-1}$ and the number of $90^{\circ}$ right angle elbows is 10 , the total resistance of the pipeline is:

$\sum H_{f}=\left(\lambda \frac{\sum l_{i}}{d}+\sum \zeta_{i}\right) \frac{u^{2}}{2 g}=\left[0.0333 \times\left(\frac{100}{0.1}\right)+10 \times 0.75\right] \times \frac{0.034^{2}}{2 \times 9.81}=0.0024 \mathrm{~m}$

Pump head is

$$
H_{e}=10+\frac{0.034^{2}}{2 \times 9.81}+\frac{9 \times 10^{5}}{1042 \times 9.81}+0.0024=98.049 m
$$


The effective power of the pump is

$$
P_{e}=q_{v} \rho g H_{e}=\frac{0.96}{3600} \times 1042 \times 9.81 \times 98.049=0.267 \mathrm{~kW}
$$

When the number of 90-degree elbows is increased from 3 to 10, it does not have much impact on the pump power requirements.

\section{CONCLUSIONS}

The pump requirements for delivering the Chlorella slurry with 5, 10, and $20 \mathrm{wt} \%$ solids at $1,000 \mathrm{~kg} / \mathrm{h}$ and $10 \mathrm{bar}$ were calculated. The $5 \mathrm{wt} \%$ microalgae slurry is a Newtonian fluid with a viscosity of $1.95 \mathrm{mPa} \cdot \mathrm{s}$. The $10 \mathrm{wt} \%$ and $20 \mathrm{wt} \%$ microalgae slurries are non-Newtonian fluid, whose viscosity depends on the shear rate $(\gamma)$. The viscosity of $10 \mathrm{wt} \%$ and $20 \mathrm{wt} \%$ microalgae slurries are $1.504\left(\gamma=50 \mathrm{~s}^{-1}\right) / 1.155(\gamma=100$

$\left.\mathrm{s}^{-1}\right)$ and $1.844\left(\gamma=50 \mathrm{~s}^{-1}\right) / 1.219\left(\gamma=100 \mathrm{~s}^{-1}\right) \mathrm{mPa} \cdot \mathrm{s}$, respectively. The pump power requirements are mainly governed by the delivery pressure. The effect of the pipe length and the number of elbows is negligible. The effective power of the pump is calculated as $0.267-0.275 \mathrm{~kW}$, and the shaft power at $70 \%$ efficiency is $0.382-0.393 \mathrm{~kW}$. To fulfill this duty, a ZGB type single-stage single-suction centrifugal slurry pump can be used.

\section{ACKNOWLEDGMENTS}

We are grateful for the support from the School of Chemical Engineering and Pharmacy at the Wuhan Institute of Technology.

\section{CONFLICTS OF INTEREST}

The authors declare that there is no conflict of interests regarding the publication of this paper.

\section{REFERENCES}

[1] Barkia, I., Saari, N., and Manning, S. R. (2019). Microalgae for High-Value Products Towards Human Health and Nutrition. Marine Drugs, 17(5), 304. DOI: 10.3390/md17050304

[2] Zhang, B., and Wang, Y. (2013). Biomass Processing, Conversion and Biorefinery, Nova Science Publishers, Inc., New York.

[3] Davis, R., Markham, J., Kinchin, C., Grundl, N., Tan, E. C., and Humbird, D. (2016). Process design and economics for the production of algal biomass: algal biomass production in open pond systems and processing through dewatering for 
downstream conversion. National Renewable Energy Lab.(NREL), Golden, CO (United States).

[4] Davis, R. E., Markham, J. N., Kinchin, C. M., Canter, C., Han, J., Li, Q., Coleman, A., Jones, S., Wigmosta, M., and Zhu, Y. (2018). 2017 Algae Harmonization Study: Evaluating the Potential for Future Algal Biofuel Costs, Sustainability, and Resource Assessment from Harmonized Modeling. National Renewable Energy Lab.(NREL), Golden, CO (United States).

[5] Allnutt, F. C. T., and Kessler, B. A. (2015). Harvesting and Downstream Processing - and Their Economics. In: Biomass and Biofuels from Microalgae: Advances in Engineering and Biology, N. R. Moheimani, et al., eds., Springer International Publishing, Cham, pp: 289-310. DOI: 10.1007/978-3-319-166407_14

[6] Hosseinizand, H., Sokhansanj, S., and Lim, C. J. (2018). Studying the drying mechanism of microalgae Chlorella vulgaris and the optimum drying temperature to preserve quality characteristics. Drying Technology, 36(9), 1049-1060. DOI: 10.1080/07373937.2017.1369986

[7] Santoro, I., Nardi, M., Benincasa, C., Costanzo, P., Giordano, G., Procopio, A., and Sindona, G. (2019). Sustainable and Selective Extraction of Lipids and Bioactive Compounds from Microalgae. Molecules (Basel, Switzerland), 24(23), 4347. DOI: 10.3390/molecules24234347

[8] Yang, C., Li, R., Cui, C., Liu, S., Qiu, Q., Ding, Y., Wu, Y., and Zhang, B. (2016). Catalytic hydroprocessing of microalgae-derived biofuels: a review.

Green Chemistry, 18(13), 3684-3699. DOI: 10.1039/c6gc01239f

[9] Yang, C., Li, R., Qiu, Q., Yang, H., Zhang, Y., Yang, B., Wu, J., Li, B., Wang, W., Ding, Y., and Zhang, B. (2020). Pyrolytic behaviors of Scenedesmus obliquus over potassium fluoride on alumina. Fuel, 263, 116724. DOI: https://doi.org/10.1016/j.fuel.2019.116724

[10] Yang, C., Li, R., Zhang, B., Qiu, Q., Wang, B., Yang, H., Ding, Y., and Wang, C. (2019). Pyrolysis of microalgae: A critical review. Fuel Processing Technology, 186, 53-72. DOI: https://doi.org/10.1016/j.fuproc.2018.12.012

[11] Zhang, B., Wu, J., Deng, Z., Yang, C., Cui, C., and Ding, Y. (2017). A Comparison of Energy Consumption in Hydrothermal Liquefaction and Pyrolysis of Microalgae. Trends in Renewable Energy, 3(1), 76-85. DOI: 10.17737/tre.2017.3.1.0013

[12] Bolhouse, A. M. (2010). Rheology of algae slurries. Master Master Thesis, University of Texas at Austin

[13] Cagney, N., Zhang, T., Bransgrove, R., Allen, M. J., and Balabani, S. (2017). Effects of cell motility and morphology on the rheology of algae suspensions. Journal of Applied Phycology, 29(3), 1145-1157. DOI: 10.1007/s10811-0161033-y

[14] Schneider, N., Fortin, T. J., Span, R., and Gerber, M. (2016). Thermophysical properties of the marine microalgae Nannochloropsis salina. Fuel Processing Technology, 152, 390-398. DOI: https://doi.org/10.1016/j.fuproc.2016.06.039

[15] Green, D. W., and Perry, R. H. (2019). Perry's Chemical Engineers' Handbook/edición Don W. Green y Robert H. Perry. 
[16] Wileman, A., Ozkan, A., and Berberoglu, H. (2012). Rheological properties of algae slurries for minimizing harvesting energy requirements in biofuel production. Bioresource Technology, 104, 432-439. DOI: https://doi.org/10.1016/j.biortech.2011.11.027

[17] Mettu, S., Yao, S., Law, S. Q. K., Sun, Z., Scales, P. J., Ashokkumar, M., and Martin, G. J. O. (2019). Rheological properties of concentrated slurries of harvested, incubated and ruptured Nannochloropsis sp. cells. BMC Chemical Engineering, 1(1), 8. DOI: 10.1186/s42480-019-0011-y

Article copyright: (c) 2020 Jiayi Li, Yinhang Qu, Yu Gong, Changyan Yang, Bohan Yang, Peng Liu, Bo Zhang, and Yigang Ding. This is an open access article distributed under the terms of the Creative Commons Attribution 4.0 International License, which permits unrestricted use and distribution provided the original author and source are credited. 